DOl: 10.21315/eimj2018.10.3.1

ARTICLE INFO

Submitted: $13-08-2018$

Accepted: 24-08-2018

Online: 28-09-2018

\section{A Review of Learning Styles in Orthodontic Education}

\author{
Gururajaprasad Kaggal Lakshmana Rao', Yulita Hanum P Iskandar², \\ Norehan Mokhtar ${ }^{1}$ \\ ${ }^{1}$ Craniofacial and Biomaterial Science Cluster, Advanced Medical \\ and Dental Institute, Universiti Sains Malaysia, Kepala Batas, \\ Pulau Pinang, MALAYSIA \\ ${ }^{2}$ Graduate School of Business, Universiti Sains Malaysia, \\ Pulau Pinang, MALAYSIA
}

To cite this article: Rao GKL, Iskandar YHP, Mokhtar N. A review of learning styles in orthodontic education. Education in Medicine Journal. 2018;10(3):1-13. https://doi.org/10.21315/eimj2018.10.3.1

To link to this article: https://doi.org/10.21315/eimj2018.10.3.1

\begin{abstract}
Learning styles among students of orthodontics has received very little importance as seen in the limited studies found in the literature. The learning styles of students form an essential part of knowledge acceptance and delivery. The present study, therefore, has identified and reviewed the learning styles used in orthodontic education to understand the methods followed by orthodontic training programmes and their implications on learning. The objective of this study is to summarise the different types of learning styles currently utilised by the faculty of orthodontics. A systematic electronic search was conducted revealing eight studies used in orthodontic training. The searches conforming to the Preferred Reporting Items for Systematic Reviews and Meta-Analyses (PRISMA) guidelines used Problem/Patient/Population, Intervention/Indicator, Comparison, Outcome (PICO) strategy for selecting the included studies. The number of studies included in this study was eight. The study analysed the different learning styles and their effects on knowledge and students' attitude. The availability of a small number of studies underscores the need to review the limited resource available to gain a better understanding of how orthodontic residents learn. This study on learning styles among orthodontic students provides a platform for building more knowledge on the learning pathways currently employed. The learning styles have an enormous influence on knowledge acquisition and retention. The study highlights the need for further exploration of the learning needs of orthodontic residents in an attempt to reveal potential benefits both for the student and the teaching faculty.
\end{abstract}

Keywords: Learning styles, Orthodontic education, Dental education, Orthodontic learning

Norehan Mokhtar \& Gururajaprasad Kaggal Lakshmana Rao, Craniofacial and Biomaterial Science Cluster, Advanced Medical and Dental Institute, Universiti Sains Malaysia, 13200 Kepala Batas, Pulau Pinang, Malaysia | Email: norehanmokhtar@usm. my/drgururajaprasad@student.usm.my

\section{INTRODUCTION}

Professional dental education involves the integration of knowledge, skills, and values towards clinical competence. The clinical competence and the development of a new skill encompass various levels of assimilating, understanding, retrieving and reflecting on acquired information (1). Learning in orthodontics occurs in a teacher-centric approach with students following the instructor's methods closely. The orthodontic training following an apprenticeship approach fails to identify 
individual traits of students (2). This lack of understanding leads to skill development based on a collective ideology. The unique attributes of the individual student are compromised. The students in order to develop their skills based on individual needs use different tools to achieve the same level of competence as required for clinical duties and responsibilities (3). The individual learning styles create a challenge in framing appropriate methods to engage a wider audience. The difference in students learning styles may be associated with an inability to understand concepts and progress. The learning styles and its understanding might provide an insight into designing appropriate teaching systems with equal representation of all styles.

The learning styles as part of the learning process and educational approach in orthodontics have not been reviewed and thereby forms the basis of this study to perform an exploration into different learning styles used in orthodontic education. The study will assess acceptance and attitudes towards various learning styles utilised in orthodontic education in an attempt to understand if learning styles influence knowledge acquisition by students. The reviewed learning styles used previously by several other authors will also help gain an understanding of the outcomes and efficiency of these styles. Therefore, the aim of this study is to review and highlight the various learning styles available for orthodontic residents and their mentors and to understand their effect on skill enhancement amongst orthodontic residents.

\section{MATERIALS AND METHODS}

An electronic search for articles in the English language was performed up to August 2018 on PubMed/Medline/ EMBASE/WorldWideWeb using Google Scholar. The keywords used for the search included orthodontics and orthodontic education and orthodontic curriculum and students learning styles and learning style assessment. The Problem/Patient/ Population, Intervention/Indicator, Comparison, Outcome (PICO) strategy was used for study inclusions. The participants included the dental undergraduate and orthodontic post-graduate students. The intervention included learning strategies employed. Comparison of different programmes was between e-learning strategies and conventional methods. The study outcomes assessed student attitudes. The search revealed a total of eight studies describing learning styles in orthodontic education. The studies will be analysed on the outcome and students' attitudes towards different learning styles.

Inclusion criteria: Only English language articles with learning styles or any form of learning strategy as an intervention in orthodontic education were chosen. Articles belonging to all types of study designs were included. Table 1 represents the search strategy used in identifying the studies for this review.

Exclusion criteria: Non-English language articles and non-orthodontic reviews were excluded.

The studies followed Preferred Reporting Items for Systematic Reviews and MetaAnalyses (PRISMA) guidelines for study inclusions (4). A total of 377 records were identified. No duplicates were found, and 369 non-relevant articles were removed as they failed to match the inclusion criteria. Title and abstract matches revealed eight articles, which were later included for a full review as represented in Figure 1.

The article screening was initially performed by one reviewer. The screening eliminated non-orthodontic studies, studies without outcome measures of knowledge gain and students' attitudes and comparison groups. The selected studies were then assessed by a second reviewer to match the inclusion criteria set forth by the authors. 
Table 1: Keywords employed in identifying the studies

\begin{tabular}{lc} 
Keywords & Number of sources found \\
\hline $\begin{array}{l}\text { Learning styles and orthodontics and orthodontic education } \\
\text { Learning styles and learning style assessment in orthodontics and } \\
\quad \text { orthodontic education }\end{array}$ & 4080 \\
$\begin{array}{l}\text { Learning styles and learning style assessment in orthodontics and } \\
\quad \text { orthodontic education and orthodontic curriculum }\end{array}$ & 909 \\
$\begin{array}{l}\text { Orthodontics and orthodontic education and orthodontic curriculum } \\
\quad \text { learning styles and learning style assessment }\end{array}$ & 425 \\
$\begin{array}{l}\text { Orthodontics and orthodontic education and orthodontic curriculum } \\
\text { and students learning styles and learning style assessment }\end{array}$ & 406 \\
$\begin{array}{l}\text { Exclusion of non-orthodontic articles } \\
\text { Studies included at title stage }\end{array}$ & 377 \\
Studies included at abstract stage & 362 \\
Studies included for full review & 15 \\
Studies included in this study & 11 \\
& 8
\end{tabular}

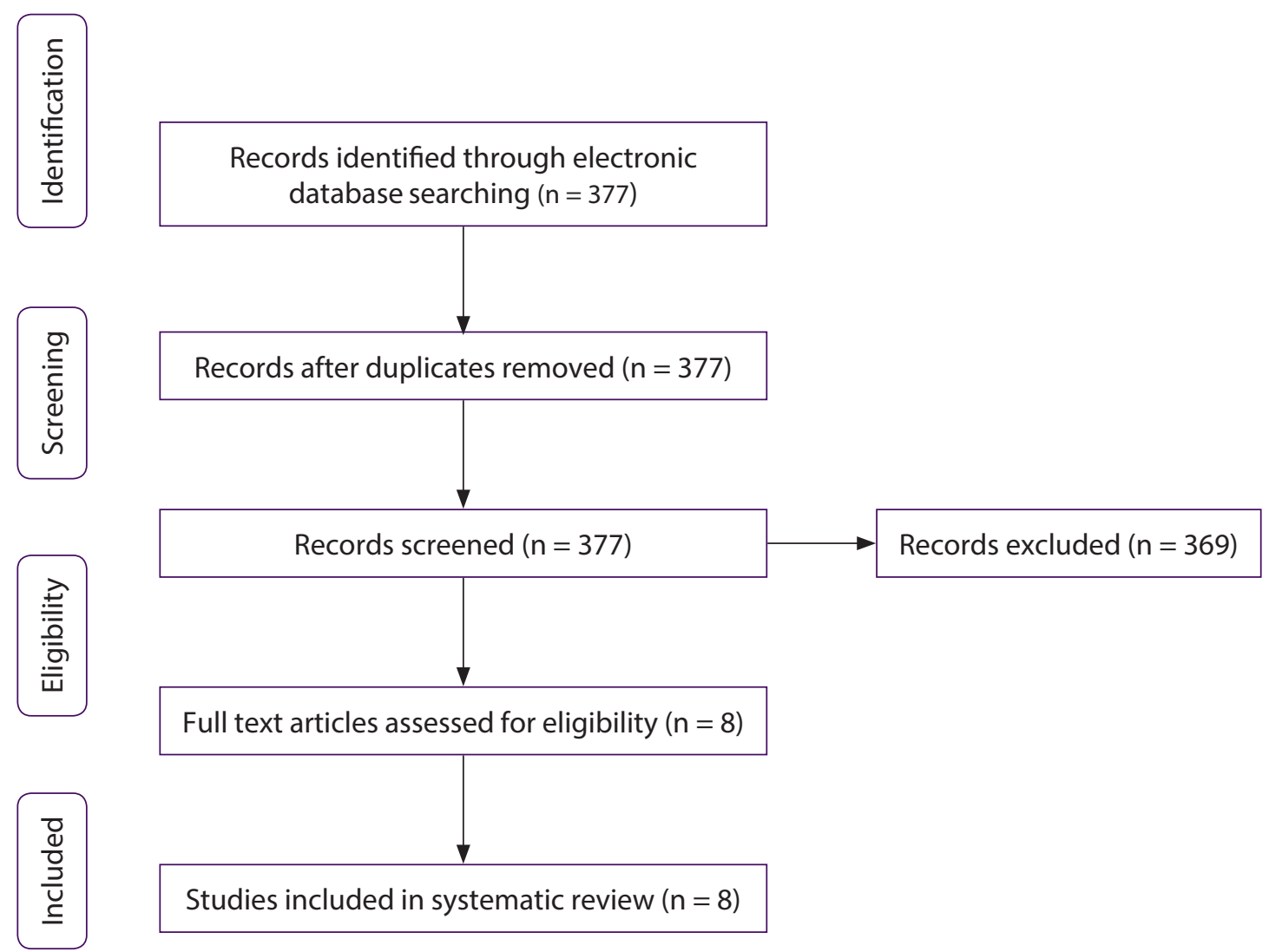

Figure 1: PRISMA flow diagram representing the inclusion of studies. 


\section{RESULTS}

The learning styles in orthodontic education review analysed eight studies conducted up to August 2018 as represented in Appendix.

All the eight studies involved evaluation of learning styles employed in orthodontic education. The different learning styles were assessed for their outcome and students' attitudes. The learning styles reviewed include "Portfolios and discussion as tools for development of reflection/Reflective e-portfolio (1, 5), Test-enhanced learning (6), Scenario-based learning interface (7), Multimedia information sequencing (8), Interactive distance learning (9), Problembased learning (PBL) (10), and Felder and Soloman's index of learning styles (11). The participants for the studies were undergraduate dental students (6) and postgraduate orthodontic students (1, 5, 7-11). Seven studies had a set amount of time as learning style intervention (1, $5-10)$. The time ranges were between thirtyfive mins (9) to one year (1). All the eight studies highlighted a positive outcome with six studies $(1,5,7,9-11)$ assessing the students' attitudes. Four studies (1, 7, 9, 11) reported that students found their learning styles effective and engaging, worthwhile and comfortable with adequate access to technological assets. One study (9) reported that $76 \%$ of responding faculty and $84 \%$ of responding residents in their study wanted to use the distance learning style again in the future whereas $(5,10)$ reported conflicting results with students experiencing acceptability issues and that PBL was a challenge which needed to be overcome as a journey and not as separate individual learning event.

\section{DISCUSSION}

The review of eight selected studies reveals unique learning styles utilised in orthodontic education. Using the PICO process, students and orthodontic residents formed the population, the intervention was through the learning styles employed, and comparison was between test and control groups with outcomes studied through knowledge gain and students' attitudes.

The learning styles of students have been shown to change as the student progresses in their academic years (12). The findings from another study suggest that the theoretical lectures and practical sessions of the preclinical training years (first- and secondyear) exhibit assimilating learning style (13, 14). This style then changes to a diverging learning style during the clinical years as ascertained by a similar study (3).

Two studies by the same author $(1,5)$ have used reflection as a means of evaluating outcomes wherein the importance of selfreflection is seen as an effective tool for the development of reflection in learning.

A thematic approach to understanding reflection, its characteristics and outcomes were studied highlighting the implementation of a reflective strategy (1). The study, however, has a limited understanding of whether the students will maintain a reflective and self-critical approach in the long term.

Reflective e-portfolio was found to have five aspects of reflection (5). The study revealed conflicting results on the acceptability. The mentors showed a positive attitude whereas the students' expressed concerns on all the five aspects of relevance, time requirement, support mentoring, implementation method, and the electronic method used. The study has drawn acceptability issues from a lack of specificity, inadequate communication amongst students, and the absence of a good relationship between mentors and students. These factors create a hindrance to the use of reflective e-portfolio in higher education.

The test enhanced approach (6) examined the outcome of students by evaluating test grades which were found to have a significant benefit at $95 \%$ confidence intervals compared to the traditional group. The test-enhanced group performance was 
better than the traditional group with more consistent demonstrations of competence with the percentage of students receiving A grades increasing by more than two confidence intervals. The study with its limitations was still able to provide an understanding of test-enhanced learning in orthodontic education with the better overall quality of grades and performance.

Scenario Based Learning interactive (SBLi) modules assessed the strengths and weaknesses of nine orthodontic modules (7). The modules were considered engaging with greater confidence in the application of clinical skills. The study limitation occurred with a very small group of nine students and hence the outcome is insignificant though provides a valuable resource on student responses on strengths and weaknesses for designing future methods of instruction.

Influence of multimedia sequencing using instructional multimedia programmes in postgraduate orthodontic training identified that hierarchical sequencing (HS) model may match the learning styles of the majority of the dental students. The HS model revealed significant learning gains and an improved estimate of posttest and gain scores in the test group when using computer-assisted learning (CAL) as a learning tool (8). The score of the test group who studied the HS modules improved by $1.75(p=0.05)$ compared with the control group. The HS models did not have any specific and significant effect on the knowledge and understanding levels of the subject matter. The outcomes of the HS model can be considered for goal-orientated sequencing in orthodontic training.

Interactive distance education

highlighted that blended learning and technology was found to be well accepted by students and faculty with $84 \%$ of the student respondents willing to use the technology again. The study highlights the inexpensive management of quality distance learning which might be the next major drift with more and more students studying online.
PBL was studied using qualitative methods to identify issues of PBL (10). The study has shown a mixed outcome with students seeing PBL as a challenge and accepting the learning cycles to be a nonindividual learning experience. The students experienced conflicts within themselves and between the group based on their positive and negative experiences with PBL.

The study utilising Felder and Soloman's index was used to identify the learning style amongst 261 survey respondents (11). The study survey received a response of $26 \%$ which might have come from individuals who were interested in education and learning styles which creates a bias in responses. The study has highlighted a very interesting aspect of learners amongst orthodontic residents with the survey revealing few global learners and more sequential learners. This answers the overall question of fewer researchers and declining number of faculty in orthodontics as the majority of sequential learners prefer to remain clinicians owing to their innate learning qualities.

Out of the eight studies reviewed, five studies have involved postgraduate students as their test subjects $(1,5,7,10,11)$. Postgraduate and undergraduate students were utilised in one study to determine the effects of hierarchical sequencing (8). A study to understand the effectiveness of testenhanced learning utilised undergraduate students entirely (6). However, the limitations of these studies are seen in the sample size employed. This limitation may be a direct result of the small number of postgraduate students enrolled in orthodontic courses as reflected in these studies $(1,5,7,10,11)$. The outcomes of these studies are difficult to generalise and thereby become insignificant for a larger application. Lack of randomisation with the absence of control and test groups was evident in one of the studies (6). The distance learning (9) might have implications for the technological limitations of internet connectivity and video playback 
options which might affect students from a resource-poor setting.

The limitations of sample size and its shortcomings can be addressed by collaborating with similarly sized cohorts from other universities nationally and globally to have a strong statistical significance. The limitations of internet connectivity have been addressed by improvements in technology and inexpensive internet globally and innovations in video playback software with a multitude of playback options.

\section{IMPLICATIONS}

It is prudent to recognise the learning styles of orthodontic students' as their perception of learning is a subject that has received little attention from dental and orthodontic educators (15). The review which reveals a sound understanding of learning strategies has many beneficial implications for both students and mentors (16). A meta-analysis (17) found a strong correlation between tailored instruction and increased academic achievement and improved attitudes to students' learning. The study highlights the importance of involving students in recognising the learning styles in an attempt to understand the effects on curriculum design matching the students unique learning strategies. Understanding these areas will not only enable the establishment of a better communication and interaction between students, faculty and the learning content (16) but also have a direct influence on the level of clinical experience (3). The identification of learning styles helps channel students with a range of learning abilities to seek newer experiences and outcomes effectively thereby improving the quality of orthodontic training. The different strategies highlighting learning styles employed for and by orthodontic residents were designed to meet a certain objective of either knowledge gain or acceptance by the students. Matching the teaching and learning styles have shown to effectively reduce the time requirements for learning a new task (18). The results from this review further contribute to the literature by identifying the strategies adopted and their influence on the outcomes of learning. The strategies; big or small will necessitate an inclusion of specific techniques supporting students' needs. Knowing these strategies will enable improved impressions of dental school experience and develop better learning pathways.

\section{CONCLUSION}

This review utilised eight studies to gain a wider understanding of the learning styles of orthodontic residents. The learning styles though are different not always contribute to a better outcome or academic performance (19). The number of studies reviewed is small which highlights the need for further exploration and studies. The learning styles and preferences should be assessed individually and collectively to seek a better understanding of how the orthodontic residents prefer the knowledge source to be disseminated. A larger study collaborating with larger cohorts from other universities nationally and globally is required to gather and establish a concrete understanding of techniques used, styles delivered, and ideas developed. This will enhance the knowledge flow and delivery utilising the right tools to integrate a particular type of learning to a particular individual or group. Developing an effective teaching method that complements a wide range of learning styles appears to be more conducive and beneficial to the overall development of orthodontic residents than attempting to tailor the course content to the individual student. This integration will further allow students to follow their own learning styles rather than follow one style employed on all. 
REVIEW ARTICLE | Learning Styles in Orthodontic Education

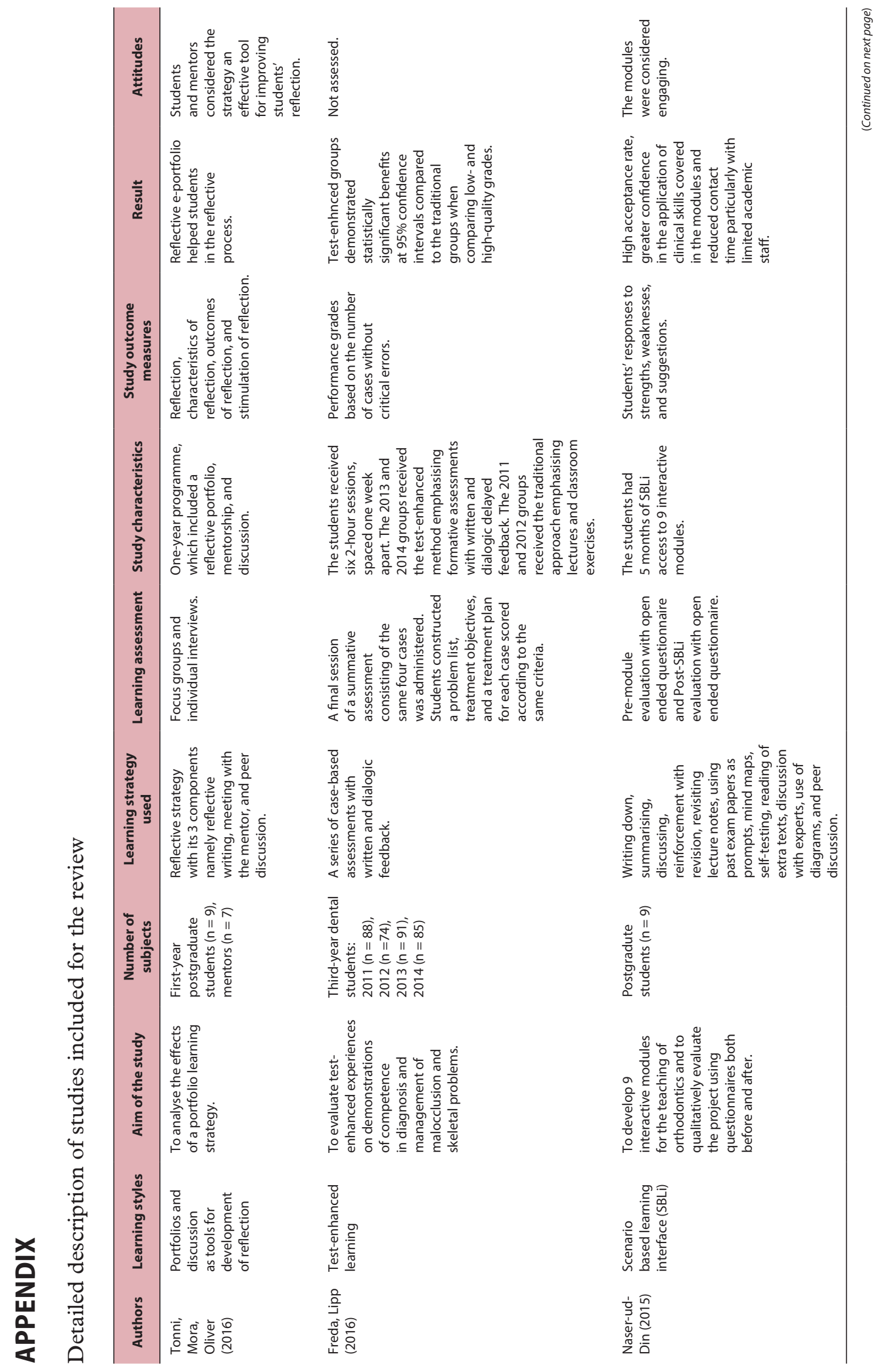




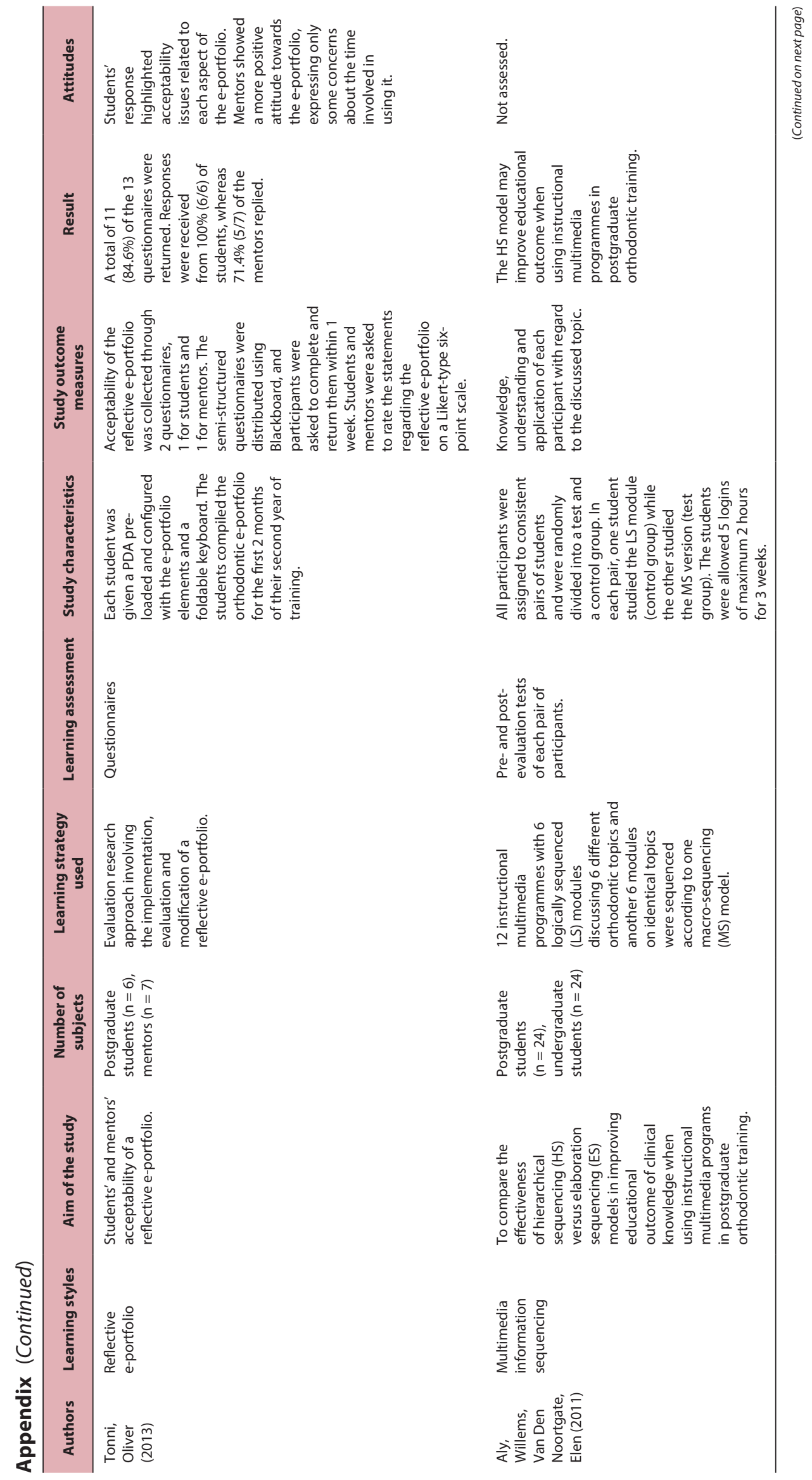




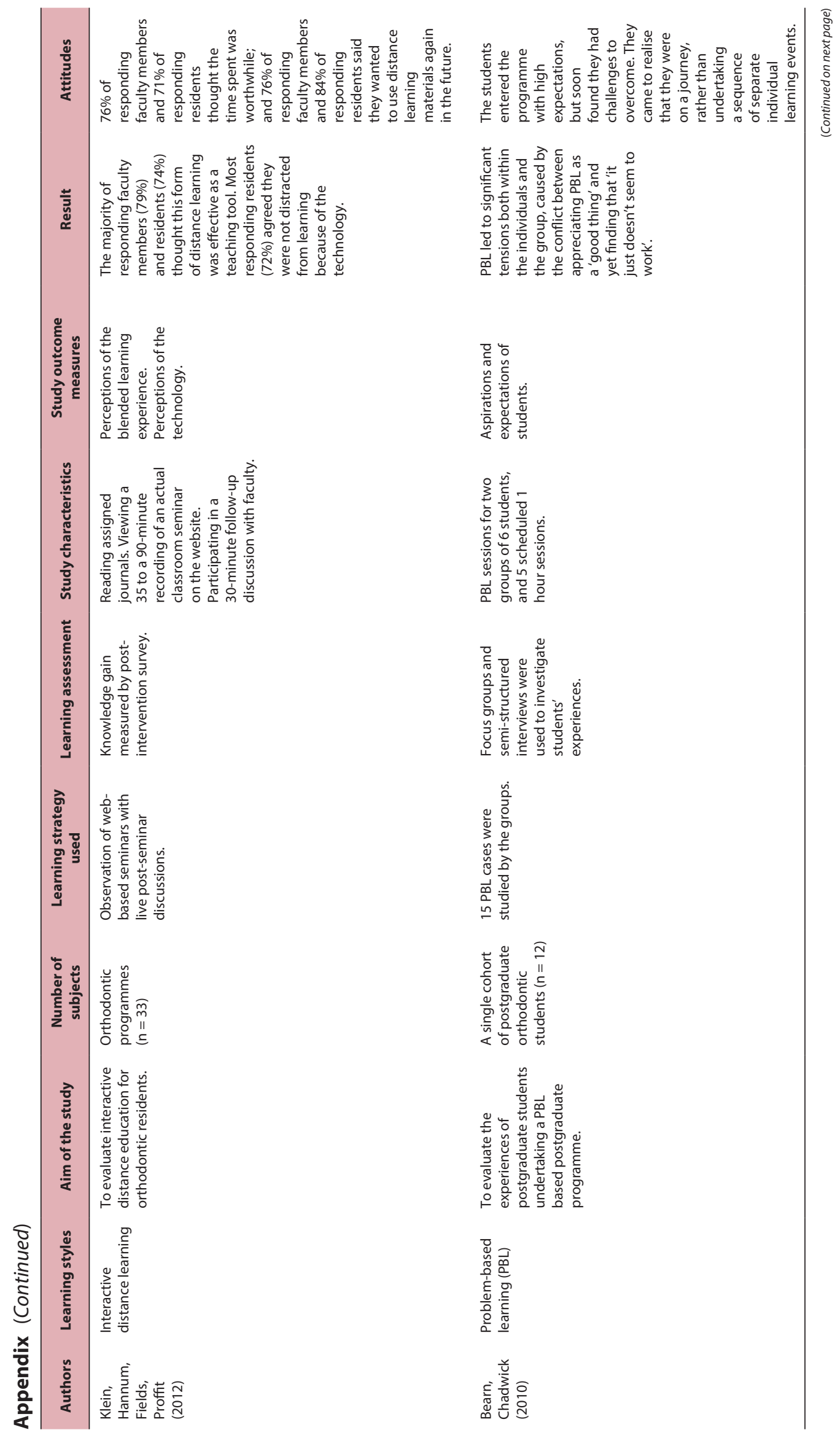




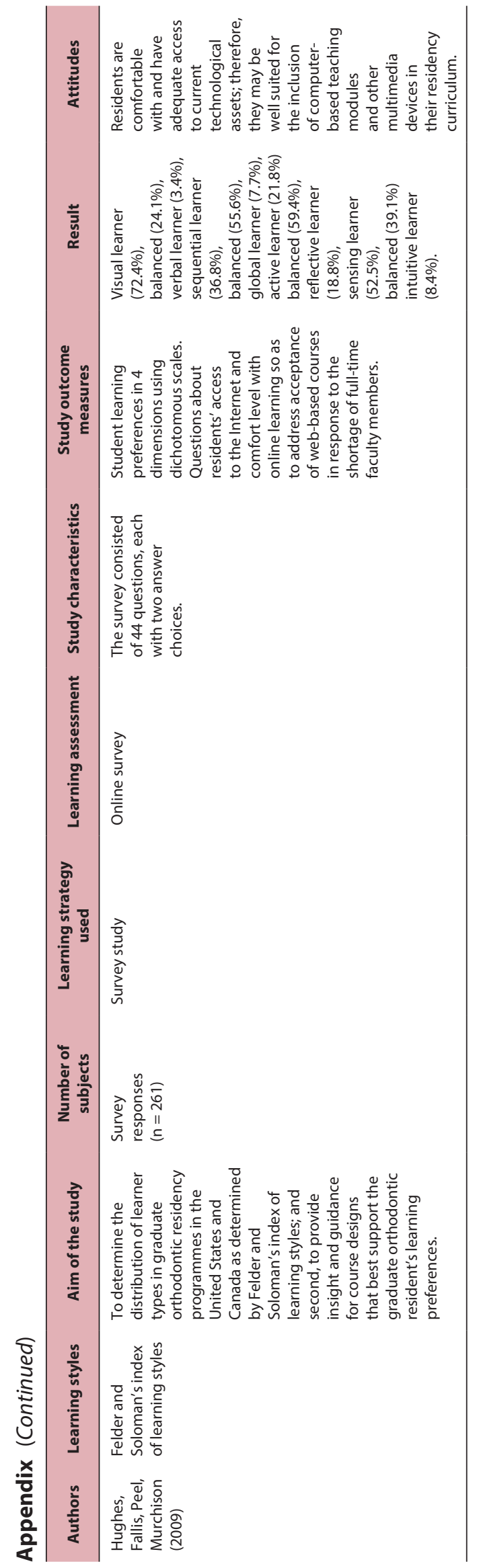




\section{REFERENCES}

1. Tonni I, Mora L, Oliver RG. Postgraduate orthodontics students' and mentors' perceptions of portfolios and discussion as tools for development of reflection. J Dent Educ. 2016;80(9):1098-108.

2. Chadwick SM, Bearn DR, Jack AC, O'Brien KD. Orthodontic undergraduate education: developments in a modern curriculum. Eur $\mathrm{J}$ Dent Educ. 2002;6(2):57-63. https://doi.org/ 10.1034/j.1600-0579.2002.60203.x

3. AL-Qahtani DA, Al-Gahtani SM. Assessing learning styles of Saudi dental students using Kolb's learning style inventory. J Dent Educ. 2014;78(6):927-33.

4. Moher D, Liberati A, Tetzlaff J, Altman DG. The PRISMA Group. Preferred reporting items for systematic reviews and meta-analyses: the PRISMA statement. PLoS Med. 2009;6(7): e1000097. doi:10.1371/journal.pmed1000097

5. Tonni I, Oliver RG. Acceptability of a reflective e-portfolio instituted in an orthodontic specialist programme: a pilot study. Eur J Dent Educ. 2013;17(3):177184. https://doi.org/10.1111/eje.12038

6. Freda NM, Lipp MJ. Test-enhanced learning in competence-based predoctoral orthodontics: a four-year study. J Dent Educ. 2016;80(3):348-54.

7. Naser-ud-Din S. Introducing scenario based learning interactive to postgraduates in UQ Orthodontic Program. Eur J Dent Educ. 2015;19(3):169-76. https://doi.org/10.1111/ eje. 12118

8. Aly M, Willems G, Van Den Noortgate W, Elen J. Effect of multimedia information sequencing on educational outcome in orthodontic training. Eur J Orthod. 2011;34(4):458-65. https://doi.org/10.1093/ ejo/cjr036
9. Klein KP, Hannum WH, Fields HW, Proffit WR. Interactive distance learning in orthodontic residency programs: problems and potential solutions. J Dent Educ. 2012;76(3):322-9.

10. Bearn DR, Chadwick SM. Problem-based learning in postgraduate dental education: a qualitative evaluation of students' experience of an orthodontic problem-based postgraduate programme. Eur J Dent Educ. 2010;14(1):26-34. https://doi.org/10.1111/ j.1600-0579.2009.00588.x

11. Hughes JM, Fallis DW, Peel JL, Murchison DF. Learning styles of orthodontic residents. J Dent Educ. 2009;73(3):319-27.

12. Bitran $\mathrm{M}$, Zúñiga $\mathrm{D}$, Pedrals $\mathrm{N}$, Padilla $\mathrm{O}$, Mena B. Learning styles of medical students change along the study program: from "thinking and watching" to "thinking and doing." Can Med Educ J. 2012;3(2):e86e97.

13. Sternberg RJ, Zhang LF, Kolb DA, Boyatzis RE, Mainemelis C. Experiential learning theory: previous research and new directions. In: Sternberg RJ, Zhang LF. Perspectives on thinking, learning, and cognitive styles. Mahwah, NJ: Lawrence Erlbaum; 2001. p. 227-47.

14. Engels PT, de Gara C. Learning styles of medical students, general surgery residents, and general surgeons: implications for surgical education. BMC Med Educ. 2010;10(1):51. https://doi.org/10.1186/14726920-10-51

15. Henzi D, Davis E, Jasinevicius R, Hendricson W, Cintron L, Isaacs $M$. Appraisal of the dental school learning environment: the students' view. J Dent Educ. 2005;69(10):1137-47.

16. Jessee SA, O'Neill PN, Dosch RO. Matching student personality types and learning preferences to teaching methodologies. J Dent Educ. 2006;70(6):644-51. 
17. Lovelace MK. Meta-analysis of experimental research based on the Dunn and Dunn model. J Educ Res. 2005;98(3):176-83. https://doi.org/10.3200/JOER.98.3.176-183

18. Stevenson J, Dunn R. Knowledge management and learning styles: prescriptions for future teachers. Coll Stud J. 2001;35(4):483-90.
19. Wilkinson T, Boohan M, Stevenson M. Does learning style influence academic performance in different forms of assessment? J Anat. 2014;224(3):304-8. https://doi.org/10.1111/joa.12126 
REVIEW ARTICLE | Learning Styles in Orthodontic Education 